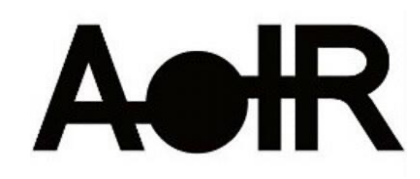

Selected Papers of \#AolR2020:

The $21^{\text {st }}$ Annual Conference of the Association of Internet Researchers

Virtual Event / 27-31 October 2020

\title{
PANEL: STUDYING YOUTH ONLINE POLITICAL EXPRESSION: EMPIRICAL FINDINGS AND METHODOLOGICAL CONSIDERATIONS
}

\author{
loana Literat \\ Teacher's College \\ Neta Kligler-Vilenchik \\ Hebrew University \\ Ellen Middaugh \\ San Jose State University \\ Mark Felton \\ San Jose State University \\ Henry Fan \\ San Jose State University \\ Ashley Lee \\ Stanford University \\ Lynn Schofield Clark \\ University of Denver \\ Carlos Jimenez \\ University of Denver
}

\section{Introduction to the Panel}

We are living through a highly politicized time, with deep divisions foregrounding the significance and importance of political expression and dialogue. Youth have been at the forefront of these important conversations, in both academic research and in the Literat, I., Kligler-Vilenchik, N., Middaugh, E., Felton, M., Fan, H., Lee, A., Clark. L.S., and Jimenez, C. (2020, October). Studying Youth Online Political Expression: Empirical Findings and Methodological Considerations. Panel presented at AoIR 2020: The 21 ${ }^{\text {th }}$ Annual Conference of the Association of Internet Researchers. Virtual Event: AolR. Retrieved from http://spir.aoir.org. 
popular press. On the one hand, we are seeing a resurgence of activism and engagement among youth (Bond, Chenoweth \& Pressman 2018; Deal 2019), who are using online platforms to express themselves politically in rich and creative ways (Graef 2016; Jenkins et al., 2016). On the other hand, deep concerns have emerged about "some of the darker sides of networked media engagement" (boyd, 2017, n.p.), including the spread of misinformation, increased polarization and politically motivated bullying among youth (Rogers, 2017).

If we see youth as active agents in their own political socialization (Youniss, McLellan \& Yates, 1997), the ways they actively express and negotiate their civic identities online (Jenkins et al., 2016) offer rich possibilities for understanding how we can best support them as civic actors. The research presented in this panel aims to move beyond a simplified depiction of youth as either idealized political role models (e.g. Greta Thunberg or the Parkland Youth) or, conversely, as apathetic and politically disengaged. In light of the conference theme exploring what it means to have a Life mediated by the internet, we place emergent and senior scholars studying youth and online political expression in dialogue with one another to discuss both findings and particular considerations brought up by Internet research (franzke et al., 2020), and especially Internet research involving youth (Livingstone \& Third, 2017). By encouraging researchers and audience members to reflect on the epistemological, ethical, and practical aspects of their own research, we aim to identify new questions for further study as we seek to understand the evolution of youth and online political expression.

The first presentation (Literat \& Kligler-Vilenchik) reviews findings from a cross-platform study utilizing a mixed methods approach to explore youth online political expression and cross-cutting political talk on TikTok, Instagram, and YouTube. These presenters discuss their findings in relation to the challenges and opportunities they encountered when identifying and analyzing youth-generated cross-platform data. The second presentation (Middaugh, Felton \& Fan) highlights findings from a social discourse analysis of Twitter and Reddit threads on youth-centric issues of immigration (DACA) and environmental issues (plastic pollution) to identify how the intersection of issue, platform and aims of discourse shape the characteristics of online civic discourse. This presenter discusses the challenges she encountered when creating both a codebook and coding scheme for data analysis. The third presentation (Lee) highlights findings emerging from a series of ethnographic interviews with young people in a comparative study exploring online youth political expression in democratic and non-democratic contexts. This presenter discusses challenges of qualitative research when working with young people, especially marginalized youth, who utilize hidden forms of expression to engage in politics. considers the role of gender and intersectional identity in online humorous political expression through a case study of a U.S. Black Muslim teen's TikTok posts. The fourth presentation (Clark \& Jimenez) presents findings from a Youth Participatory Action Research (YPAR) project that involved researchers and youth in the creation of "productive disruptions" designed to disrupt and productively reframe conversations about racism and injustice. The presenters explore how adults can partner with political newcomers to both support and to better understand youth online political engagement. Our joint video aims to generate discussion for future research into the study of youth political expression online. 


\section{References}

Bond, K., Chenoweth, E., \& Pressman, J. (2018, April 13). Did you attend the March for our Lives? Here's what it looked like nationwide. Washington Post. Retrieved from https://www.washingtonpost.com/news/monkey-cage/wp/2018/04/13/did-you-attendthe-march-for-our-lives-heres-what-it-looked-like-nationwide/

boyd, d. (2017). Learning all the wrong things. Keynote lecture presented at the Digital Media \& Learning Conference, Irvine, CA, 2017. Retrieved from https://dml2017.dmlhub.net/live/

Deal, J. (2019, November 18). Youth political engagement and hope ahead of the 2020 election (Harvard Public Opinion Project). Harvard Political Review. Retrieved from https://harvardpolitics.com/united-states/youth-political-engagement-and-hope-aheadof-the-2020-election/

franzke, a., Bechmann, A., Zimmer, M., Ess, C., \& the Association of Internet Researchers (2020). Internet Research: Ethical Guidelines 3.0. Retrieved from https://aoir.org/reports/ethics3.pdf

Graef, E. (2016). Youth digital activism. In Youth Civic Engagement: United Nations World Youth Report. New York, NY: United Nations, pp. 95-107.

Jenkins, H., Shresthova, S., Gamber-Thompson, L., Kligler-Vilenchik, N. and Zimmerman A. (2016). By any media necessary: The new youth activism. New York: NYU Press.

Livingstone, S., \& Third, A. (2017). Children and young people's rights in the digital age: An emerging agenda. New Media \& Society 19(5), 657-670.

Rogers, J. (2017). Teaching and learning in the age of Trump: Increasing stress and hostility in America's high schools. UCLA's Institute for Democracy, Education, and Access. Retrieved from https://idea.gseis.ucla.edu/publications/teaching-and-learningin-age-of-trump

Youniss, J., Bales, S., Christmas-Best, V., Diversi, M., McLaughlin, M. \& Silbereisen, R. (2002). Youth civic engagement in the twenty-first century. Journal of Research on Adolescence, 12(1), 121-148. 


\title{
YOUTH COLLECTIVE POLITICAL EXPRESSION AS PROMPTED BY POPULAR CULTURE: A SOCIAL MEDIA CROSS-PLATFORM ANALYSIS
}

\author{
loana Literat, Ph.D. \\ Teacher's College \\ Neta Kligler-Vilenchik, Ph.D. \\ Hebrew University
}

\section{Introduction: Social Media, Popular Culture, and Youth Political Expression}

The centrality of social media as a space for youth self-expression (boyd, 2014) presents a valuable opportunity to study their political expression in naturally occurring contexts. Yet the variance in how different platforms afford or constrain political expression (e.g. Lane et al., 2018; Stromer-Galley, Bryant \& Bimber, 2015) points at the importance of cross-platform approaches, including ones focusing on the social media platforms most popular with youth today.

When youth political voice occurs naturally, in their preferred spaces, it is often contextualized within young people's areas of interest (Jenkins et al., 2016). In the current US context, when political polarization is at peak levels, there is a need to understand how to best encourage political dialogue that reaches productively across party divisions (Kahne \& Bowyer, 2017). Contextualizing politics within popular cultureas is often done on social media-may serve as a shared symbolic resource that can engage youth. Here, we investigate this potential by examining the role of popular culture in stimulating youth political expression and discussion in the social media spaces most popular with youth.

\section{Methods}

To do so, we undertake a comparative, cross-platform analysis of youth interaction across political differences on three social media platforms (YouTube, Instagram and TikTok), chosen due to their popularity with youth and their shared emphasis on visual/audio-visual content. Across these platforms, our case study revolves around the concept of building Donald Trump's proposed border wall within the popular videogame Fortnite. This idea has become a popular internet meme, manifested across social media platforms and through different text genres; tracking it across three platforms allows for an insightful cross-platform analysis of political expression and discussion.

To holistically understand these dynamics, we combine in-depth qualitative and quantitative content analysis of 6,398 comments posted on the six top commented artifacts across platforms. For quantitative content analysis, we developed a codebook to code comments for political content, political view (pro-Trump, anti-Trump, or unclear/neutral), politeness, and civility. For threads, we also coded for cross-cutting political talk. Comments and artifacts were then analyzed qualitatively, using a grounded theory approach. 


\section{Findings and Discussion}

Our analysis showed that popular culture content-here, the world of Fortniteprompted significant political expression on both TikTok (with $44 \%$ political comments) and YouTube (40\%), and to a lesser extent on Instagram (4\%), likely shaped by platform norms. Across platforms, youth contextualized their political stances through connections to the imaginary Fortnite world, which enabled them to praise, criticize, or mock Donald Trump, while metaphorically conveying their views about a policy issuethe proposed border wall with Mexico-and its ramifications.

At the same time, the resulting picture of political expression and dialogue is fairly bleak, with little cross-cutting exposure, and a general lack of productive cross-cutting dialogue. Even the symbolic resources from the world of Fortnite (e.g. avatar skins, construction of walls) were often used in disparaging ways to enforce social stereotypes (e.g. of Mexicans or immigrants vs "real Americans"), in contrast to the more idealized view of the civic imagination (Jenkins et al., 2016).

Our cross-platform analysis thus suggests that the bridging potential of popular culture interacts with the divisive potential of cross-cutting political talk; and that the way this plays out is shaped by the content, norms, and affordances of different social media platforms (see Figure 1). While our cross-platform approach was exploratory, we did find notable differences between the platforms in the extent to which they spurred political comments, the political orientation of these comments, and the resulting crosscutting talk. The most striking case here is Instagram. While the Instagram artifacts were of a political nature comparable to the artifacts on the other platforms, it seems that the norms and affordances of Instagram exerted a depoliticizing influence. We therefore conceive of these elements as shaping —-though not determining-resulting youthcross-cutting political talk as prompted by popular culture. 




Figure 1. The interplay between popular culture, cross-cutting political talk and social media in shaping youth online political expression and conversation

\section{Elaborated Methodological Discussion}

In this panel, in addition to our findings, we would like to discuss pertinent methodological considerations that came up in our study, and that are relevant to researching youth political expression on social media.

One key consideration surrounded the creation of our corpus for analysis. A crossplatform analysis of political discussion required a case that is 1) politically-relevant, 2) clearly youth-oriented, and 3 ) appears on each of the three sites. In practice, however, identifying content that fit all three criteria was challenging. To address all three points, we tried to identify political texts emanating from youth popular culture, which led us-after much searching - to the popular meme imagining the construction of Trump's border wall within Fortnite. At the same time, focusing on this case study brought up challenges in terms of generalizability, e.g., in terms of considering to what extent our insights are shaped by the particular context of Fortnite. 
From a data analysis perspective, our mixed-methods design shows both strengths and weaknesses. On the one hand, the quantitative coding aided our qualitative analysis, as it enabled us to split the corpus of comments by political vs. non-political content, and within political content, to look separately at Trump supporters, opponents, and their cross-cutting conversations. The two approaches were thus complementary: the quantitative analysis provided a birds-eye-view of the data and hinted at cross-platform differences, while the qualitative analysis allowed us to understand this data holistically. However, due to the comments' relation to specific media artifacts, the quantitative analysis did not allow us to generalize to all (political) expression on these platforms, but only to hint at areas where cross-platform differences may occur.

Finally, we can question how our chosen methods shaped our conclusions in regard to youth political expression on social media. Our study design sought out content connecting popular culture and politics, which obviously represents only a subset of youth expression online - yet our method does not allow investigating how common it in fact is. Conceptually, we argue popular culture might serve as symbolic resources that allow even non-politically engaged youth to connect to politics and participate in discussions around political topics. Yet our approach still puts a focus on those youth who choose to express themselves politically and enter these conversations, leaving open the question of how to study and understand the youth whose voices are not represented.

\section{References}

boyd, d. (2014). It's complicated: The social lives of networked teens. New Haven: Yale University Press.

Jenkins, H., Shresthova, S., Gamber-Thompson, L., Kligler-Vilenchik, N. and Zimmerman A. (2016). By any media necessary: The new youth activism. New York: NYU Press.

Kahne, J., \& Bowyer, B. (2017). Educating for democracy in a Partisan age: Confronting the challenges of motivated reasoning and misinformation. American Educational Research Journal, 54(1), 3-34.

Lane, D. S., Das, V., \& Hiaeshutter-Rice, D. (2018). Civic laboratories: youth political expression in anonymous, ephemeral, geo-bounded social media. Information, Communication \& Society, 1-16.

Stromer-Galley, J., Bryant, L. \& Bimber, B. (2015). Context and medium matter: Expressing disagreements online and face-to-face in political deliberations. Journal of Public Deliberation 11(1), Article 1. 


\title{
BUILDING PRODUCTIVE ONLINE CIVIC DISCOURSE: EXAMINING THE INTERSECTION OF PLATFORM, ISSUE AND INDIVIDUAL AIMS
}

\author{
Ellen Middaugh, Ph.D. \\ Mark Felton, Ph.D. \\ Henry Fan, Ph.D. \\ San Jose University
}

Participation in public discourse has long been understood as critical to the ongoing project of democratic renewal. Discourse allows us to connect and coordinate with those with aligned views and understand, negotiate or compete with those with divergent views. Accordingly, educators view these as habits and skills to be encouraged and supported in youth (Hess \& McAvoy, 2014). As public discourse moves online, we must understand how this shift changes the practice of public discourse and what understandings and skills are needed for youth to participate as informed, ethical and empowered citizens.

Research provides mixed portraits of online public discourse. Social network sites have been found to facilitate connections between those with shared political interests, creating opportunities to quickly connect one's own political concerns to a larger public (Bruns \& Burgess, 2015), which may increase access to relevant information, strengthen political identity, and provide opportunities to engage in collective action. Simultaneously, numerous studies have responded with concerns about the quality of online civic discourse amongst everyday citizens, particularly as it relates to the prevalence and impact of incivility, misinformation, and polarization, all factors which can hinder participation in discourse and inhibit engagement with those with divergent views (e.g. Alcott et al, 2019; Vraga et al, 2015; Dubois \& Blank, 2018). These studies suggest persistent presence of incivility and misinformation, with mixed findings on prevalence and impact, and mixed findings regarding polarization.

At this point, research can provide educators with a set of evidence-based possibilities and challenges to guide their work with youth. However, the practice of intentionally cultivating productive online discourse requires more specific information about what such discourse looks like and the conditions under which it is most likely to occur.

To address these needs, this study uses social discourse analysis of social media threads on youth relevant civic issues to identify "productive" examples of online civic discourse and examine factors that support the emergence of dialogue. This study is Phase I of a multi-phase design research study, which will culminate in the implementation and research of an undergraduate course to support students in cultivating online civic dialogue about social issues, coinciding with the US Presidential election. 


\section{Method}

This phase of the study relied on a grounded theory approach, appropriate for the discovery and identification of new theoretical distinctions. We began with the basic question of, "Where do we see evidence of productive online discourse emerging?" The first step of the sampling process involved an exploratory review of multiple platforms (e.g. Instagram, Tiktok, YouTube), threads of high profile young activists (e.g. Mari Copany, Emma Gonzalez), and issues (e.g. gun control, tuition reform, immigration, unemployment) during which time the authors kept field notes of observations of pertinent qualities of discourse, such as dialogic aims of participants, appearance of transactive dialogue, qualities of exchanges.

From there, we narrowed our focus to identifying cases with exchanges where 2+ people responded to each other and our sampling to social media threads on two youthrelevant issues (Immigration/DACA \& Environmental Protection/Plastic Pollution) from two different platforms (Twitter and Reddit). The issues were chosen for their relevance to youth in the study location and their potential to provide useful analytic contrast (based on observations during the exploratory step). Platforms were chosen for the presence of transactive dialogue during the exploratory step and their contrasting features and affordances for supporting transactive dialogue.

Both authors engaged in axial coding of an initial subset of data focusing on the identification of of transactive dialogue (Berkowitz \& Gibbs, 1983) or dialogue in which participants engaged with each other's reasoning. Authors deductively examined tweets and reddit posts for the presence of dialogic moves (e.g. critique, elaboration, metadialogic commentary) informed by Author 2's previous coding of face-to-face dialogue, democratic aims (e.g. mobilizing action, building coalitions, debating issues) informed by on Author 1's prior research on youth online civic practices, and dialogic qualities (e.g. use of evidence, outrage language, escalation or dismissiveness) informed by both. Additionally, the authors coded inductively, revising the coding system to account for emerging phenomena, for example @ing other users to expand the conversation, offering identity disclosure to establish credentials or affiliation.

Exploratory analysis of potential data sources and iterative axial coding of the initial subset of data yielded useful insights, shared below, regarding how to better define "productive" online civic discourse and factors that enable such discourse. In the final version, findings from systematic deductive coding of the corpus of data using social discourse analysis will be shared to compare the qualities of discourse emerging between platform \& issue.

\section{Findings \& Implications}

The findings thus far highlight a few important considerations for identifying and cultivating productive online civic discourse. For example, the dialogic aims of public discourse (information seeking, influence, affiliation, dialogue, debate, mobilization) varied, with implications for how we define "productive" online discourse. The conversationals requirements for maintaining an intensive dialogue or debate differ from those of engaging in discourse to influence the public narrative or strengthen affiliative 
ties. Additionally, platform matters, with different platforms providing different levels of support for the varied dialogic aims identified. Twitter and Reddit were chosen intentionally for their organizational differences, so findings of differences in the ease of identification of transactive dialogue are not surprising, but when placed in juxtaposition with dialogic aims provide greater clarity about how individuals might approach and make decisions about their own participation in online public discourse. The contrast between dialogue about Immigration/DACA vs. Environmentalism/Plastic pollution also suggests that certain issues may provide more leverage for initiating and elaborating transactive dialogue. The final version of the paper will build on these insights and provide results from the deductive coding to illustrate examples of conversational characteristics that align with transactive dialogue in each condition (issue $\mathrm{x}$ platform).

\section{Extended Methodological Discussion}

One strength of this study is the development of a detailed coding system to enable analysis of how social dynamics and contexts of discourse (e.g. the intersection of issue, platform and dialogic aim) intersect to facilitate or hinder the emergence of transactive dialogue and use of evidence and the conversational strategies that individuals employ to manage these dialogues. The discussion will focus on how the sampling and coding approach provides analytic advantages as well as more precise guidance for educators and how this approach may also cut off opportunities to identify important new phenomena in online civic discourse.

\section{References}

Alcott, H., Gentzkow, M. \& Chuan, Y. (2019). Trends in the diffusion of misinformation on social media. Research and Politics, 1-8.

Berkowitz, M. W., \& Gibbs, J. C. (1983). Measuring the developmental features of moral discussion. Merrill-Palmer Quarterly, 29:4, 399-410.

Bruns, A. \& Burgess, J. (2015). Twitter hashtags from ad hoc to calculated publics. In N. Rambukkana (Ed.) Hashtag Publics: The Power and Politics of Discursive Networks

Dubois, E. \& Blank,G. (2018). The echo chamber is overstated: the moderating effect of political interest and diverse media. International Journal of Communication, 729-45.

Hess, D. \& McAvoy, P. (2014). The political classroom: Evidence and ethics in democratic education. Routledge Press.

Vraga, E., Thorson, K., Kligler-Vilenchik, N. \& Gee, E. (2015). How individual sensitivities to disagreement shape youth political expression on Facebook. Computers in Human Behavior, 45: 281-89. 


\title{
MEDIA ACTIVISM BELOW THE RADAR: YOUTH AND HIDDEN RESISTANCE IN THE DIGITAL AGE
}

\author{
Ashley Lee, Ph.D.
}

Stanford University

\section{Study Context and Rationale}

Around the world, young people are leveraging social media to engage with political issues outside the confines of traditional public institutions (e.g. voting). Initially, this shift seemed to signal enormous potential for democratic renewal globally, with the emergence of new political actors and new modes of political engagement. While the rise of networked public spheres presents new opportunities for youth who were previously excluded from formal channels of political participation, digital platforms may also subject youth to surveillance, censorship, and other forms of repression. This study investigates how young people in three countries-Canada (a strong democracy), the United States (a democracy under stress), and Cambodia (a non-democracy)leverage social media for political participation. Drawing on in-depth interviews and surveys with 91 young activists (ages 18-30), I examine how young activists incorporate social media tactics into their political repertoires, as they navigate the emergent dynamics of state and corporate surveillance in the digital world.

Emerging studies suggest a necessary rethinking of traditional notions of citizenship and political participation, particularly in light of alternative and creative avenues offered online (e.g. Bennett, 2008; Bennett \& Segerberg, 2012; Kahne, Middaugh \& Allen, 2015; Jenkins et al., 2016). A considerable amount is known about social media tactics young people use in liberal democracies under the conditions of free press and healthy civil society (e.g. Clark \& Marchi, 2017; Jenkins et al., 2016; Literat \& Kligler-Vilenchik, 2018). However, to build a more diverse account and theory of participatory politics, it is necessary to take a more inclusive approach that considers youth in different social, political contexts.

\section{Methods}

I conducted 91 in-depth interviews with youth who considered themselves to be politically active across the three countries. In all three countries, I used purposive sampling, targeting diverse youth, ages 18-30, who are actively engaged in social movements and contentious politics. Since I was interested in understanding social media practices and lived experiences of digitally active, civic-minded youth, I selected young media activists who use (or have used) social media extensively across a spectrum of contentious politics and issues, in various roles. In all, my sample for each country consisted of diverse youth from a broad range of racial and socio-economic backgrounds.

Each interview lasted, on average, 90-120 minutes. The interviews and short surveys were conducted after obtaining informed consent from the participants. With permission 
from the participants, the interviews were recorded with a digital audio recorder and transcribed in full, some by the author and the majority by transcribers and speech recognition software. The interviews incorporated social media walkthroughs, in which participants were invited to walk me through their social media profiles and talk about media artifacts they created as part of their activism. The survey included items about the respondents' present and past political activities (both online and offline), as well as values, motivations, attitudes, and beliefs that underlie their participation patterns. Data collection and analysis took place in tandem, and analytical strategies were modified as new data and analyses became available. In line with the analytical strategy of the grounded theory, I developed coding categories inductively and refined them in parallel with data analysis (Charmaz, 2006; Glaser \& Strauss, 1967).

\section{Findings and Discussion}

I find that even in democracies like the United States and Canada, for individuals along various axes of marginalization (e.g. political, social), public displays of political action do not capture the full range of political expression on social media. My analysis shows how young people strategically adopt social media tactics that keep their political acts partially or wholly hidden, in response to the pressures of state, corporate, and social surveillance. This phenomenon of "flying under the radar" is particularly salient among youth in the repressive regime (Cambodia) who adopt hidden tactics (e.g. using coded images) on social media to engage in contentious politics without being caught or sanctioned by the government. These findings offer insights into how young activists seek to exert influence on public issues using social media in highly contentious, highrisk political climates. Further, I find that in this moment of increasing inequality and polarization, even in liberal democracies, many young people, especially those from marginalized groups, adopt indirect, hidden tactics that are comparable to those I found in the non-democratic country (Cambodia). This study develops conceptual and analytical tools to highlight the voices of subaltern communities that have been obscured by the more traditional focus on public spaces and forms of participation.

\section{Elaborated Methodological Discussion}

In addition to my empirical findings, I will discuss methodological considerations that came up in my study. In particular, I discuss opportunities and challenges associated with the interviews and social media walkthroughs. During the interview, participants were invited to walk me through their social media profiles, and talk about media artifacts they created as part of their activism. I use this method to observe participants' everyday use of social media platforms and understand the ways in which participants may appropriate social media platforms for their own political purposes. A key strength of this method is allowing the researcher to be attentive to young people's own understandings and reasons for their political expression and actions. I also discuss how the walkthrough method might be employed in an ethical way while respecting the confidentiality and privacy of participants. 


\section{Bibliography}

Bennett, W. L. (2008). Changing citizenship in the digital age. In W. L. Bennett (Ed.), Civic life online: Learning how digital media can engage youth (pp. 1-23). Cambridge, MA: MIT Press.

Bennett, W. L. \& Segerberg, A. (2012). The logic of connective action. Information, Communication \& Society, 15(5): 739-768.

Charmaz, K. (2006). Constructing grounded theory: A practical guide through qualitative analysis. Thousand Oaks, CA: Sage.

Clark, L. S. \& Marchi, R. (2017). Young people and the future of news. Cambridge, UK: Cambridge University Press.

Glaser, B., \& Strauss, A. (1967). The discovery of grounded theory. Chicago, IL: Aldine.

Jenkins, H., Shresthova, S., Gamber-Thompson, L., Kligler-Vilenchik, N., \& Zimmerman, A. (2016). By any media necessary: The new youth activism. New York, NY: NYU Press.

Kahne, J., Middaugh, E., \& Allen, D. (2015). Youth, new media, and the rise of participatory politics. In D. Allen \& J. S. Light (eds.) (2015). From voice to influence: Understanding citizenship in a digital age (pp. 35-58). Chicago, IL: University of Chicago Press.

Literat, I. \& Kligler-Vilenchik, N. (2018). Youth online political expression in non-political spaces. Learning, Media \& Technology 43(4): 400-417. 


\title{
CREATING PRODUCTIVE DISRUPTIONS: EMPLOYING MEDIA-RICH YPAR FOR CRITICAL DIGITAL LITERACY DEVELOPMENT AMONG YOUNG TEENS
}

\author{
Lynn Schofield Clark, Ph.D. \\ Carlos Jimenez, Ph.D. \\ University of Denver
}

\section{Introduction:}

This paper develops the concept of media rich Youth Participatory Action Research (YPAR) by reviewing a project that brought together researchers, university students, and junior high aged young people to explore the incorporation of TikTok and Instagram into a communication campaign designed to address systemic racism. The concept builds on Youth Participatory Action Research methodologies, which are rooted in critical race approaches that emphasize the development of local rather than expert knowledge and have grown out of efforts to challenge neoliberal educational interventions (Cammarota \& Fine, 2010).

The intergenerational team developed a working definition of what we came to call Productive Disruptions: stories or posts that challenge a dominant narrative, raise awareness about an important issue, and help disrupt and productively reframe a conversation (Jimenez 2020). Social media has proven to be an important entry point to political engagement for political newcomers (Clark \& Marchi, 2017; Jenkins et al., 2016; Literat \& Kligler-Vilenchik, 2018). This paper therefore contributes to discussions of youth online political engagement by exploring how such engagement came to occur and what was learned about engagement among newcomers to politics who were between the ages of 14 - 16 years old.

\section{Method}

The authors of this paper partnered with The Bridge Project, an after school enrichment program that provided academic and leadership development support in YPAR programs for school-aged BIPOC and White young people living in economically precarious neighborhoods. In the Productive Disruptions project that took place in the summer of 2020, we recruited 10 young people, most from Bridge. There were 8 females and 2 males. They identified as Black (3), Asian (3), Latinx (1), White (3), and 2 identified with the LGBT community. Most lived in Denver's most economically precarious communities. Several had struggled with mental and cognitive challenges. These young people worked with 5 university-age mentors who identified as White (4) and Latinx (1), with 1 identifying with the LGBT community. Each of these young people had participated in a course that introduced them to critical race pedagogies and critical race media criticism (Ramirez, 2020). They also met with 6 university- and graduatelevel researchers - 4 males, 2 females - who identified as White (4), Latinx (1), and mixed race Latinx and White (1). All of the mentors and members of the research team 
were trained in recognizing power, privilege, and oppression, and participated in weekly sessions of accountability that included discussions of lived and systemic racism and reflections on our own privileges and biases.

The group of 21 participants met multiple times each week over zoom for the 16-week project. During the first 8 weeks, the research team and young people shared and discussed examples of social media posts that they believed were particularly compelling statements about racism. The murder of George Floyd took place in the fifth week of these meetings, and thus they began focusing intensely on sharing \#BlackLivesMatter events, videos, and other materials. They discussed what they liked about the posts and what they believed that the creators of those posts might have hoped that viewers would do in response to the posts, questions that came to form the rubric by which they evaluated the creations that they, their peers, and their mentors created on a weekly basis after the mentors joined them in the 7th week. We then created joint accounts under the name of Youth Productive Disruptors (@YouthDisruptors) on Twitter, Instagram, and TikTok so that young people could share their creations yet preserve their anonymity. This strategy addressed both youth and caregiver concerns about the need to limit the potential for online harassment and surveillance, as young people did not use their own accounts although they could repost from the joint account to their own account if they chose.

\section{Findings and Discussion}

As the rash of armed counterprotests at 2020 \#BlackLivesMatter events and as police shootings of Black men at those events have demonstrated, young people of color face heightened risks that they will encounter state and police-sanctioned violence and harassment when engaging in political activities (Lee, 2018; Philimon, 2020). BIPOC young people are also more likely than their white peers to be cynical about existing political systems (Gordon \& Taft, 2011). They also have heightened concerns about surveillance, and for good reason (Carbado, 2017; Fine et al., 2003). But even with these risks, some BIPOC young people still express a great deal of interest in engaging in political participation (Hope et al., 2016).

Our work affirmed prior research that has found that young Black, Indigenous and people of color (BIPOC) in the U.S. face numerous barriers to engaging civic and political action. We found that the young people we worked with were especially drawn to Productive Disruptions that presented knowledge from feminist, Black, and intersectional identity perspectives. They recognized that Productive Disruptions worked best when they were consistent with the social media genre, and they appreciated the use of humor. However, their greatest energy was devoted to sharing information with their peers. What surprised us was a preference for detailed infographics among several youth, as this departed from the familiar social media genres. What also surprised us was the need for discussions about avoiding cultural appropriation, which led to thoughtful reconsideration and more sensitive productions. 


\section{Conclusion}

Many young BIPOC and white young people from economically precarious neighborhoods will experiment online without adults. But for young people who face the greatest barriers to political participation, our research found that adults can play a key role. We can create brave spaces of support that allow for discussing our own experiences with racism, discrimination, and privilege both off and online that then inform research. We can help young people think through the ownership limitations and business models of TikTok, Instagram, and Twitter as well as how to avoid harassment and negative consequences, for example by creating collective online accounts that preserve anonymity. And we can leverage our ages and positions to connect young people to the policymakers who might otherwise be beyond their reach, which will be a topic for our future research thanks to the policymakers who took note of the Productive Disruptions produced.

We argue that it is important to explore participatory methodological efforts in the context of internet and social media research for a number of reasons. First, participatory methodologies have been particularly important among communities of color, as they center the lived experiences of those communities and are grounded in the belief that unearthing, articulating, and leveraging community-based knowledge is foundational to transforming social inequalities in the contexts of those communities (Friere, 1970). Second, by foregrounding issues of lived racial experiences, the traditions of participatory methodological work have long addressed ethical issues of race in research, such as how White researchers, as well as all of those conducting research in the settings of Predominantly White Institutions (PWI), can best live out commitments to mutuality and respect in relation to the practices of generating and sharing research findings(Bailey et al., 2019). Third, as participatory methodologies create bridges between "expert" and "local" knowledge, we argue that they hold promise in relation to the rethinking of existing "expert" theories: in this case, those of how and why Black, Indigenous, and other young people of color might or might not participate in online political action, and the role that researchers of Predominantly White Institutions might play in these processes as they also seek to understand them. Such work is mandated within contemporary critical approaches to decolonizing and radicalizing research(Bonilla-Silva, 2017; Fanon, 2007; Mackey, 2016). As an approach that has garnered interest among those in critical media literacy studies (Mihailidis, 2018; Ramasubramanian, 2016), it is important to place into dialogue with scholarship on race and internet studies (Benjamin, 2019; Brock, 2020; Florini, 2019; Gray, 2014; Jackson, Bailey \& Welles, 2019; Lu \& Steele, 2019; Nakamura \& Chow-White, 2013; Noble, 2018) (Benjamin, 2019; Brock, 2020; Florini, 2019; Gray, 2014; Mcllwain, 2019; Nakamura and Chow-White, 2013; Noble, 2018).

This methodology is limited, as noted in other research that has interrogated the failures as well as the promises of the YPAR model (see Burke et al., 2017; Clark, 2016), and who have noted the need to avoid sensationalism and oversimplification (Soep, 2014). Nevertheless, we believe that this methodology does hold promise for reframing questions of BIPOC youth involvement in online political engagement, and may also provide support for young people who want to make a difference in our communities and our world. 
References:

Bailey, J., Steeves, V., Burkell, J., Regan Shade, L., Ruparelia, R., \& Regan, P. (2019). Getting at Equality: Research Methods Informed by the Lessons of Intersectionality. International Journal of Qualitative Methods, 18, 160940691984675. https://doi.org/10.1177/1609406919846753

Benjamin, R. (2019). Race After Technology: Abolitionist Tools for the New Jim Code. Polity.

Bonilla-Silva, E. (2017). Racism without Racists: Color-Blind Racism and the Persistence of Racial Inequality in America, Fifth Edition. Rowman \& Littlefield Publishers. https://rowman.com/isbn/9781442276239/racism-without-racists-color-blindracism-and-the-persistence-of-racial-inequality-in-america-fifth-edition

Burke, K. J., Greene, S., \& McKenna, M. K. (2017). Youth Voice, Civic Engagement and Failure in Participatory Action Research. The Urban Review, 49(4), 585-601. https://doi.org/10.1007/s11256-017-0410-4

Cammarota, J., \& Fine, M. (2010). Revolutionizing Education: Youth Participatory Action Research in Motion. Routledge.

Carbado, D. W. (2017). From Stopping Black People to Killing Black People: The Fourth Amendment Pathways to Police Violence. California Law Review, 105(1), 125-164.

Clark, L. S. (2016). Participant or Zombie? Exploring the limits of the participatory politics framework through a failed media-rich Youth Participatory Action Research (YPAR) Project. The Information Society, 32(5), 343-353.

Clark, L. S., \& Marchi, R. (2017). Young People and the Future of News: Social Media and the Rise of Connective Journalism. Cambridge University Press.

Fanon, F. (2007). The Wretched of the Earth. Grove/Atlantic, Inc.

Fine, M., Freudenberg, N., Payne, Y., Perkins, T., Smith, K., \& Wanzer, K. (2003). "Anything Can Happen With Police Around": Urban Youth Evaluate Strategies of Surveillance in Public Places. Journal of Social Issues, 59(1), 141-158. https://doi.org/10.1111/1540-4560.t01-1-00009

Florini, S. (2019). Beyond Hashtags: Racial politics and Black digital networks. New York University Press.

Friere, P. (1970). Pedagogy of the oppressed. Herder and Herder

Gordon, H. R., \& Taft, J. K. (2011). Rethinking Youth Political Socialization: Teenage Activists Talk Back. Youth \& Society, 43(4), 1499-1527. https://doi.org/10.1177/0044118X10386087 
Hope, E. C., Keels, M., \& Durkee, M. I. (2016). Participation in Black Lives Matter and deferred action for childhood arrivals: Modern activism among Black and Latino college students. Journal of Diversity in Higher Education, 9(3), 203-215.

https://doi.org/10.1037/dhe0000032

Jenkins, H., Shrestova, S., Gamber-Thompson, L., Kligler-Vilenchik, N., \& Zimmerman, A. (2016). By Any Media Necessary. NYU Press.

http://nyupress.org/books/9781479899982/

Lee, A. (2018). Invisible networked publics and hidden contention: Youth activism and social media tactics under repression. New Media \& Society, 20(11), 4095-4115. https://doi.org/10.1177/1461444818768063

Literat, I., \& Kligler-Vilenchik, N. (2018). Youth online political expression in non-political spaces: Implications for civic education. Learning, Media and Technology, 43(4), 400417. https://doi.org/10.1080/17439884.2018.1504789

Lu, J. H., \& Steele, C. K. (2019). 'Joy is resistance': Cross-platform resilience and (re)invention of Black oral culture online. Information, Communication \& Society, 22(6), 823-837. https://doi.org/10.1080/1369118X.2019.1575449

Mackey, J. (2016, September 13). A Racial Autobiography of Race in Social Science Spaces: Reflections of My Early Understandings of Race and Racism. Harvard Kennedy School Journal of African American Policy.

http://hjaap.hkspublications.org/2016/09/13/a-racial-autobiography-of-race-in-socialscience-spaces-reflections-of-my-early-understandings-of-race-and-racism/

Mihailidis, P. (2018). Civic Media Literacies (1 edition). Routledge.

Nakamura, L., \& Chow-White, P. (2013). Race After the Internet. Routledge.

Noble, S. U. (2018). Algorithms of oppression: How search engines reinforce racism. New York University Press.

Philimon, W. (2020, July 7). Black Americans report hate crimes amid Black Lives Matter gains. USA TODAY.

https://www.usatoday.com/story/news/nation/2020/07/07/black-americans-report-hatecrimes-amid-black-lives-matter-gains/3259241001/

Ramasubramanian, S. (2016). Racial/ethnic identity, community-oriented media initiatives, and transmedia storytelling. The Information Society, 32(5), 333-342. https://doi.org/10.1080/01972243.2016.1212618

Soep, E. (2014). Participatory Politics: Next-Generation Tactics to Remake Public Spheres (1 edition). The MIT Press. 